\title{
Reproductive and family planning history, knowledge, and needs: A community survey of low-income women in Beijing, China Hong $\mathrm{He}^{* 1}$, Truls Østbye ${ }^{2,3}$ and Anne K Daltveit*4
}

\author{
Address: ${ }^{1}$ Institute of health studies, School of Sociology and Population Studies, Renmin University of China, Beijing, PR China, ${ }^{2}$ Duke-NUS \\ Graduate Medical School, Department of Community, Singapore, ${ }^{3}$ Family Medicine, Duke University, USA and ${ }^{4}$ Department of Public Health and \\ Primary Health Care, University of Bergen, Norway \\ Email: Hong He* - hehong@ruc.edu.cn; Truls Østbye - ostby001@mc.duke.edu; Anne K Daltveit* - anne.daltveit@isf.uib.no \\ * Corresponding authors
}

Published: 10 August 2009

BMC Women's Health 2009, 9:23 doi:10.1 I86/1472-6874-9-23
Received: 17 April 2009

Accepted: 10 August 2009

This article is available from: http://www.biomedcentral.com/l472-6874/9/23

(C) 2009 He et al; licensee BioMed Central Ltd.

This is an Open Access article distributed under the terms of the Creative Commons Attribution License (http://creativecommons.org/licenses/by/2.0), which permits unrestricted use, distribution, and reproduction in any medium, provided the original work is properly cited.

\begin{abstract}
Background: The reproductive health status of China's low-income urban women is believed to be poor. Therefore, understanding their reproductive history and needs and improving services provision is very important. However, few studies have been done to assess reproductive health status, knowledge and needs in this low-income population. The purpose of this study is to broadly assess reproductive and family planning history, knowledge and health needs among low income urban women with an aim to informing health services interventions.
\end{abstract}

Methods: 1642 low-income women age 18-49 from Haidian district, Beijing were selected. All were interviewed via a standardized questionnaire in 2006.

Results: Most women reported at least one pregnancy and delivery $(97.7 \%, 98.3 \%)$. Deliveries in hospitals $(97.3 \%)$ by medical personnel $(98.5 \%)$ were commonplace, as was receipt of antenatal care $(86.0 \%)$. Nearly half had at least one abortion, with most $(56.0 \%)$ performed in district hospitals, by physicians (95.6\%), and paid for out-of-pocket (64.4\%). Almost all (97.4\%) used contraception, typically IUDs or condoms. Reproductive knowledge was limited. Health needs emphasized by the participants included popularizing reproductive health information, being able to discuss their reproductive health concerns, free reproductive health insurance, examination and treatment.

Conclusion: Among poor urban women in Beijing, antenatal care and contraceptive use were common. However, abortions were also common. Knowledge about reproductive health was limited. There is a need for better reproductive health education, free medical care and social support.

\section{Background}

Living conditions for low-income urban populations in China is, in general, less favorable than for other urban dwellers. In the largest cities, Beijing and Shanghai, the physical environment is often poor and there is a lack of stable and safe housing arrangements [1,2]. The low- income population in urban areas is mostly comprised of individuals affected by the recent economic transition. They include laid-off workers from state owned enterprises, registered unemployed urban residents, retired workers without pension, and disabled persons who are usually unemployed [3]. 
Since 1993, China has gradually implemented a system of income guarantees, which provides relief for citizens whose per capita income is under the minimum income level. Between January and June 2003, more than 7.1 billion Yuan (about 855 million US dollars) was distributed to 21.8 million poor urban Chinese people with less than the minimum income level [4]. Still, their access to health care, especially to hospital care, is limited because of the lack of health insurance and disposable income to pay out-of-pocket medical care costs [4].

In 1994, World Health Organization (WHO) defined reproductive health as a state of physical, mental, and social well-being in all matters relating to the reproductive system at all stages of life, without any diseases or discomfort [4]. Reproductive health is a basic precondition for a good life, and also for the health of future generations. General strengthening of reproductive health and of family planning services has repeatedly been stated as a priority for reducing maternal mortality and improving maternal and child health in China [5].

To meet these goals, departments of family planning have been established in all districts of China. So far, little systematic research has been done to assess reproductive and family planning history, knowledge and needs in the lowincome population. This population is likely at higher risk of health problems. In spite of greater needs, they may receive less health services. Therefore, a better understanding of reproductive health service use and needs within this population is crucial for improving services and subsequently for improving health, whether through private or governmental action.

The objective of this study was to better understand the reproductive health history among low-income urban women in the Haidian district of Beijing, China. Specifically, we investigated women's reproductive and family planning history, knowledge, needs, and their suggestions for improving their own reproductive health.

\section{Methods \\ Study setting}

Participants for this study were recruited from the Haidian district in Beijing, situated in the northwestern part of the greater urban area. It is 431 square $\mathrm{km}$ in area, making it the second-largest district in urban Beijing, and home to 2.24 million inhabitants (2000 Census).

Cross-sectional data were used to assess the reproductive health of a low-income urban population in Haidian. Study participants completed one survey in the summer of 2006. To be eligible for the survey, participants needed to be associated with one of the 29 neighborhood committees or streets in Haidian, and have an average monthly income below the official low-income level (330 Yuan or $\$ 42$ U.S. per month). A list of all eligible individuals was obtained from the Ministry of Civil Affairs. The study was approved by the Human Research Ethics Committee of China, and informed consent was obtained prior to collecting survey data. Data analyses for this report were exempted from full review by Duke University Medical Center's Institutional Review Board.

\section{Sampling procedures}

A list of all neighborhood committees or streets in this district, with their total number of low-income persons, was generated before the start of the study. Due to differences in the proportion of low-income population in the various neighborhood committees or streets, a probability proportional to size (PPS) sampling method was applied to achieve a representative sample [6]. If an individual refused participation, an alternate subject was selected from the same neighborhood committee or street. Among all eligible participants, as identified in the registry for the survey, 3007 persons were randomly selected to be recruited for the study. In total, 2895 subjects completed the questionnaire, including 1025 men and 1870 women. Because of the nature of our research and the significantly shorter questionnaire administered to men, only the 1642 women of reproductive age (aged 18-49 in our sample) were included in these analyses.

\section{Field work}

Interviewers were trained by the researchers prior to entering the field. Researchers also supervised the field work to ensure that standard procedures were followed. The researchers checked all completed questionnaires daily, and mistakes were corrected immediately.

All interviews were scheduled ahead of time, in the company of the neighborhood committee or street administrator. If a participant was unavailable for any reason at the time of the appointment, the appointment was rescheduled. If the participant was unavailable at the second appointment, another person from the same neighborhood committee or street was randomly selected as a replacement participant.

\section{Questionnaire}

The questionnaire was comprised primarily of closedended questions that queried participants' basic demographic characteristics, such as age, education, marital status and job status; general self-reported health status; reproductive health history; reproductive knowledge; and health needs. Never-married women are usually reluctant to answer questions relating to pregnancy, abortion, delivery and contraception. As a result, these items were only asked of married or formerly married women. For contraceptive methods, the respondent was asked to report her 
current most commonly used method of contraception. Post-menopausal women were asked to report the contraceptive method used previously. No clinical examination was included.

\section{Present study}

The present study is based on survey data from 1642 women aged 18-49, representing a sample fraction of $20 \%$ of the total low-income female urban population in the district. The main outcome measures were reproductive health history (data on pregnancies, deliveries and abortions) reproductive health knowledge (a series of 11 questions), and health needs. For health needs, the respondents were asked to give priority to a maximum of three of 14 possible choices.

\section{Statistical analysis}

The analysis program Epidata3.1 was used for data entry, checking, and processing. Consistency and range checks were made and errors were corrected in Epidata before exporting to SPSS 11.5 for analysis. Analyses included descriptive statistics, such as frequency tables and inferential statistical analysis in the form of cross tabulations. Main results are presented in tables stratified by age. All statistical tests (chi-square tests for difference between proportions) were two-sided, and $\mathrm{p}<0.05$ indicated significant differences.

\section{Results}

\section{Characteristics}

Overall, $96.0 \%$ were of Han ethnicity, $82.6 \%$ had junior middle school education or higher, $77.9 \%$ were married, $82.3 \%$ were unemployed, $93.1 \%$ depended on subsidy for living, and $43.5 \%$ were sick or disabled (Table 1).

\section{Reproductive health history- pregnancy, delivery and abortions}

For married and formerly married females, we tabulated pregnancies, deliveries and abortions by age. Overall, $97.7 \%$ had at least one pregnancy, and $47.4 \%$ had two or more pregnancies (Table 2 ). The vast majority of deliveries $(97.3 \%)$ took place in hospitals and were attended by medical personnel (98.5\%), and $86.0 \%$ of the pregnant woman received antenatal care. Younger females had fewer pregnancies and deliveries, and were more likely to deliver in a hospital.

Nearly half of the females had had at least one abortion, and nearly $14.6 \%$ had more than one (Table 2 ). More than half of the abortions were performed in district hospitals, $95.6 \%$ by a physician, and $64.4 \%$ had paid out of pocket for the procedure.
Table I: Subject characteristics

\begin{tabular}{|c|c|c|}
\hline & Count $(n=1642)$ & $\%$ \\
\hline \multicolumn{3}{|l|}{ Age group (years) } \\
\hline $18 \sim 29$ & $|4|$ & 8.6 \\
\hline $30 \sim 39$ & 625 & 38.1 \\
\hline $40 \sim 49$ & 876 & 53.3 \\
\hline \multicolumn{3}{|l|}{ Ethnicity } \\
\hline Han & 1576 & 96.0 \\
\hline Minority & 66 & 4.0 \\
\hline \multicolumn{3}{|l|}{ Education } \\
\hline Illiterate or semiliterate & 100 & 6.1 \\
\hline Elementary school & 186 & 11.3 \\
\hline Junior middle school & 642 & 39.1 \\
\hline Senior middle school & 617 & 37.6 \\
\hline Junior college and above & 95 & 5.8 \\
\hline \multicolumn{3}{|l|}{ Marital status } \\
\hline Unmarried & 126 & 7.7 \\
\hline Married & 1279 & 77.9 \\
\hline Divorced & 144 & 8.8 \\
\hline Widowed & 92 & 5.6 \\
\hline \multicolumn{3}{|l|}{ Job status } \\
\hline Unemployment & 1351 & 82.3 \\
\hline Employment & 291 & 17.7 \\
\hline \multicolumn{3}{|l|}{ Income source } \\
\hline Subsidy & 1529 & 93.1 \\
\hline Other & 113 & 6.9 \\
\hline \multicolumn{3}{|l|}{ Numbers of family members } \\
\hline I & 74 & 4.5 \\
\hline 2 & 342 & 20.8 \\
\hline $3+$ & 1227 & 74.7 \\
\hline \multicolumn{3}{|l|}{ Convenience } \\
\hline Both kitchen and toilet & 1074 & 65.4 \\
\hline Either kitchen or toilet & 246 & 17.7 \\
\hline Neither kitchen nor toilet & 233 & 16.8 \\
\hline \multicolumn{3}{|c|}{ General self-reported health status } \\
\hline Healthy & 746 & 45.4 \\
\hline "Sub-healthy" & 181 & 11.0 \\
\hline Sick or disabled & 715 & 43.5 \\
\hline
\end{tabular}

\section{Contraception}

Only married and formerly married women were included in the analyses relating to contraception (Table 3 ). The youngest couples were more likely to use contraception. The most common contraception methods were intrauterine device (IUD) and condoms. Sterilization was more commonly reported in the older age group ( $\mathrm{p}<$ $0.01)$.

\section{Reproductive health knowledge}

A series of reproductive health knowledge questions were asked (Table 4) about harmful effects on health. The majority of women $(64.7 \%)$ thought abortions were harmful to health, $15.8 \%$ and $27.5 \%$ women believed that contraception and sterilization were harmful to health, respectively. 
Table 2: Reproductive history among ever married by age group

\begin{tabular}{|c|c|c|c|c|}
\hline & $\begin{array}{r}\text { I8 29 years } \\
(n=55)\end{array}$ & $\begin{array}{r}30 \sim 39 \text { years } \\
(n=609)\end{array}$ & $\begin{array}{r}40 \sim 49 \text { years } \\
(n=848)\end{array}$ & $\begin{array}{r}\text { Total } \\
(n=15 / 2)\end{array}$ \\
\hline \multicolumn{5}{|l|}{ Numbers of pregnancies } \\
\hline 0 & 15.4 & 2.4 & 1.4 & 2.3 \\
\hline I & 50.0 & 50.8 & 50.0 & 50.3 \\
\hline 2 & 19.2 & 30.7 & 31.7 & 30.8 \\
\hline $3+$ & 15.4 & 16.2 & $16.9 * *$ & 16.6 \\
\hline \multicolumn{5}{|l|}{ Deliveries } \\
\hline \multicolumn{5}{|l|}{ Numbers } \\
\hline 0 & 4.4 & 2.6 & 0.9 & 1.7 \\
\hline I & 93.3 & 93.1 & 91.0 & 91.9 \\
\hline 2 & 2.2 & 3.8 & 8.0 & 6.1 \\
\hline 3 & 0 & 0.5 & $0.1 * *$ & 0.3 \\
\hline \multicolumn{5}{|l|}{ Place } \\
\hline Public hospital & 100 & 95.7 & 96.6 & 96.4 \\
\hline Private hospital & 0 & 1.3 & 0.6 & 0.9 \\
\hline At home & 0 & 3.0 & 2.8 & 2.8 \\
\hline \multicolumn{5}{|l|}{ Delivery Personnel } \\
\hline Medical personnel & 100 & 98.5 & 98.5 & 98.5 \\
\hline Family members & 0 & 1.1 & 0.9 & 1.0 \\
\hline Relatives and friends & 0 & 0.4 & 0.6 & 0.5 \\
\hline Antenatal care (yes) & 88.4 & 87.4 & 85.0 & 86.0 \\
\hline \multicolumn{5}{|l|}{ Abortion } \\
\hline \multicolumn{5}{|l|}{ Numbers } \\
\hline 0 & 57.8 & 52.7 & 53.5 & 53.3 \\
\hline I & 26.7 & 32.1 & 32.6 & 32.2 \\
\hline 2 & 13.3 & 12.3 & 11.3 & 11.8 \\
\hline $3+$ & 2.2 & 2.9 & 2.7 & 2.8 \\
\hline \multicolumn{5}{|l|}{ Place } \\
\hline City hospital & 50.0 & 35.7 & 33.1 & 34.6 \\
\hline District hospital & 38.9 & 56.0 & 56.7 & 56.0 \\
\hline Family planning service station & 11.1 & 8.3 & 10.2 & 9.4 \\
\hline \multicolumn{5}{|l|}{ Operation personnel } \\
\hline Doctor & 88.9 & 97.0 & 94.8 & 95.6 \\
\hline Assistant doctor & 11.1 & 1.9 & 3.8 & 3.2 \\
\hline Nurse & 0 & 1.1 & 1.4 & 1.2 \\
\hline \multicolumn{5}{|l|}{ Payment } \\
\hline Free & 22.2 & 18.5 & 37.7 & 29.4 \\
\hline Paid $50 \%$ & 11.1 & 3.0 & 8.5 & 6.3 \\
\hline Paid full & 66.7 & 78.5 & $53.8^{* *}$ & 64.4 \\
\hline
\end{tabular}

Note: Numbers in cells are column percentages. Chi-square tests: $*^{*} p<0.01$ among age groups.

Table 3: Contraceptive use among ever married by age group

\begin{tabular}{|c|c|c|c|c|}
\hline & $\begin{array}{r}\text { I8 29 years } \\
(n=55)\end{array}$ & $\begin{array}{r}30 \sim 39 \text { years } \\
(n=609)\end{array}$ & $\begin{array}{r}40 \sim 49 \text { years } \\
(n=848)\end{array}$ & $\begin{array}{r}\text { Total } \\
(n=\mid 5 / 2)\end{array}$ \\
\hline Using contraception & 100.0 & 96.9 & 97.7 & 97.4 \\
\hline \multicolumn{5}{|l|}{ Contraception methods } \\
\hline Oral contraceptives & 2.0 & 3.4 & 5.1 & 4.3 \\
\hline IUD & 30.0 & 45.4 & 53.4 & 49.2 \\
\hline Condom & 66.0 & 42.3 & 30.1 & 36.5 \\
\hline "Safe" period & 0 & 2.4 & 2.6 & 2.4 \\
\hline Sterilization & 2.0 & 6.0 & 7.7 & 6.8 \\
\hline Other & 0 & 0.6 & $1.0^{* *}$ & 0.8 \\
\hline
\end{tabular}

Note: Numbers in cells are column percentages. Chi-square test: $*_{p} p<0.01$ among age groups. 
Table 4: Reproductive health knowledge

\begin{tabular}{lr}
\hline & Count $(n=1642)$ \\
\hline Do you think the following are harmful to health? (numbers and \% saying yes) & \% \\
$\quad$ Abortion & 1062 \\
Contraception & 259 \\
$\quad$ Sterilization & 15.8 \\
Have you received satisfactory information about the following? (yes) & 27.5 \\
Adolescent health care & 452 \\
Prevention of unwanted pregnancy for adolescent & 701 \\
Prevention of STD and AIDS & 609 \\
Contraception knowledge for newly married & 37.1 \\
Healthy pregnancy and delivery & 69.8 \\
Maternal health care & 63.7 \\
Birth control and contraception for married couples & 7146 \\
Menopausal health care & 1046 \\
\hline
\end{tabular}

Abbreviations: STD: sexually transmitted diseases, AIDS: Acquired Immure Deficiency Syndrome.

The proportion who felt they had received satisfactory information about reproductive health issues ranged from $32.8 \%$ (information about menopausal health care) to 74.3\% (information about Maternal health care).

\section{Health Needs}

The respondents were also asked whether they had any suggestions for improvements to reproductive health service or access to service (Table 5).

Reproductive health needs identified by participants included: 1) popularizing reproductive health information, 2) being able to discuss their reproductive health concerns, 3) provision of free reproductive health care and health insurance, and 4) provision of home aid or assistance services for the disabled. Almost $7.9 \%$ of respondents would like the government to provide a free reproductive health examination every two years. Respondents also expressed a need for societal support, including higher subsidies, greater technical training, and assistance in finding employment.

\section{Discussion}

The low-income population in China has gradually increased from under one million in 1997 to 22.36 millions in 2007 [3]. This population presents reproductive health issues that merit attention from the public health authorities. This study provides an overview of reproductive health history, knowledge and needs as expressed by low-income, urban women in a district of Beijing.

The majority $(98.3 \%)$ of women had had at least one delivery. $6.4 \%$ and $0.3 \%$ of the women had two and three or more children, respectively. The average number of deliveries among low-income urban women was 1.05 children per person, which is lower than the number (1.43) reported by urban married women in the 2001 national survey [7]. The proportion of older women who had two or more children was $8.1 \%$, which is significantly

Table 5: Most important health and social needs reported

\begin{tabular}{lr}
\hline Suggestions & Count $(n=1642)$ \\
\hline Popularize information regarding reproductive health & 419 \\
Discuss their reproductive health concerns & 25.5 \\
Free reproductive health examination every two years & 24.6 \\
Free treatment for disease in the reproductive system & 7.9 \\
Provide free medical insurance for reproductive health & 3.8 \\
Provide home service for the disabled & 130 \\
Improve healthy service communication skills & 62 \\
Eliminate discrimination against disabled people & 47 \\
Eliminate gender discrimination & 2.9 \\
Strengthen societal support & 42.2 \\
Increase subsidies & 2.5 \\
Provide technical training & 1.9 \\
Provide low-rate loans & 3.1 \\
Provide help for job searches & 5.1 \\
\end{tabular}


higher than among younger women (2.2\%). This finding is related to family planning policies of China where, in the early 1980s, the central government advocated one child per family in urban areas, with some flexibility for certain regions and for minorities.

As many as $97.3 \%$ reported that the delivery had taken place in a hospital, and $98.5 \%$ had their child delivered by medical personnel. These results are similar to those reported in the general population [8]. The proportion of women who reported receiving antenatal care at least once was $86.0 \%$ in our study, a finding significantly lower than that found among urban married women nationally (96.4\%) [9]. However, it was still higher than what has been reported in rural areas of China (85.6\%) [9] or worldwide (over 70\%) [10]. Antenatal care is essential to detect and follow up early risk factors for pregnancyrelated complications and diseases.

Nearly half of all the women surveyed had had at least two pregnancies and one abortion; nearly $15 \%$ reported having had an abortion twice; $2.8 \%$ reported three or more abortions. $81.9 \%$ of married urban women had at least one abortion, and $13.8 \%$ had three or more abortions [11]. Almost ninety-eight percent of subjects reported using some form of contraception; this is higher than that reported by married (83.4\%) and "floating" married females (90.6\%) [12] [Note: the term "floating" is often used in China for individuals moving from rural hometowns to large cities. Even so, abortion rates are high, suggesting that contraceptive methods used were ineffective. Abortion is legal in China, so it may sometimes be used as a method of birth control by individuals with limited reproductive health knowledge. Health education, especially around contraception, should therefore be enhanced in this population, emphasizing the risk of complications from abortions, and that it should only be used when other contraceptive methods fail.

The prevalence of contraceptive use in this population was $97.4 \%$, higher than the national prevalence reported in 1992 among married women (83.5\%) [13]. In our study, $49.2 \%$ of couples used an IUD and $36.5 \%$ of couples used condoms. Guo Sufang et al found similar IUD use (50.6\%) among married women in 2003 [14]. Xiao Wanchun found a proportion as high as $73.8 \%$ among rural females [15]. The IUD is an efficient, safe, low-cost, and reversible contraceptive method. The proportion reporting having been sterilized in our study was very low $(6.8 \%)$, and more commonly reported in the older age group. This low rate may be related to increasing government provision of various safe, efficient, reversible, and low-cost contraceptive methods.
Assessing reproductive health knowledge of low-income women is important as this can reveal the extent to which women are aware of various health problems they may face and whether they might seek help. Although the respondents report some reproductive knowledge, it was quite limited. $35.3 \%$ of the women did not think abortion is harmful to health; this is lower than in an earlier national survey of urban females (49.7\%) [13]. Lowincome women have fewer opportunities for getting necessary information, so easier access to reproductive health education should be a priority.

The most frequently reported needs relating to reproductive health were popularization of reproductive health information, being able to discuss their reproductive health concerns, and free reproductive health insurance, medical examination and treatment. Given these women's limited financial resources, they may be less able to pay for health services. Moreover, the women want stronger societal support in general and the elimination of gender discrimination in particular.

Reproductive health is a key component of overall health. Since many low-income women do not seek medical care because of their limited income, strategies for making the medical system accessible and affordable should be developed [3].

This study is one of the first investigations of reproductive health and family planning history, knowledge and needs of urban low-income women in Beijing, and provides a foundation for developing strategies to improve this vulnerable population's reproductive health status. This study's main limitation is the reliance of self report. The study targeted the low-income population - it would have been of interest (but beyond the resources for the current study), to compare the findings to middle and higherincome women. Some events reported may, especially for older respondents, have taken place long ago.

\section{Conclusion}

Among these urban low-income women, antenatal care and contraceptive use were common. However, abortions were also common and reproductive health knowledge was limited. There is need for better reproductive health education, free medical care and social support among these women.

\section{Competing interests}

The authors declare that they have no competing interests.

\section{Authors' contributions}

$\mathrm{HH}$ took part in the collection of data, analyzed and interpreted data, and drafted the manuscript. TØ and AKD critically reviewed the analysis and interpretation of data, and 
contributed to the revisions of the manuscript. All authors read and approved the final version of the manuscript.

\section{Acknowledgements}

We are most grateful to the Family Planning Committee of Haidian for providing support for this survey. The authors are particularly indebted to the students Shang-Jing Yin and Qiao Yu for their assistance in data collection and preparation. Thanks to Delana Orr for helpful editing.

\section{References}

I. Yun C: The study of community provides help for urban lowincome population. Hospital Management Forum 2003, 22:35-40.

2. Zhang B: The survey of urban low-income population condition in X district of Beijing. Journal of Beijing Institute of Planning Labour Administration 2006, 14:23-24.

3. Ministry of Civil Affairs of the People's Republic of China Report of Ministry of Civil Affairs of China in 2003 [http:// www.china.org.cn/english/GS-e/I8I344.htm]. March 27, 2009

4. Zhang H, Liu R: A survey and solution to medical insurance system among low-income population in Nanjing. Modern Medical Journal 2003, $31: 58-59$.

5. Zheng $X Y$ : Introduction to reproductive health. Beijing: China Population press; 1997:25-26.

6. Reproductive Health Response in Conflict Consortium [http://www.rhrc.org/resources/general fieldtools/toolkit/ 55b\%20pps\%20sampling\%20technique.doc]

7. $\mathrm{Qu} J \mathrm{D}$, Therese H: Family size, fertility preferences, and sex ratio in China in the era of the one child family policy: results from a national family planning and reproductive health survey. England Medical Journal (Chinese Version) 2006, 9:209-2I2.

8. Li F, Shi SH, Yang WF: Progress in women on reproductive health. Foreign Medical Sciences (maternal child health care) 200I, 12:97-99.

9. Health Statistical Center, Ministry of Health of China: 2004. Health service research: the report on the 3rd National Health Service Survey. Beijing: Peking Union Medical College Press; 2004.

10. World Health Organization (WHO) and United Nations Children's Fund (UNICEF). In Antenatal Care in Developing Countries: Promises, Achievements and Differentials, 1990-200I Geneva: World Health Organization; 2003.

II. Zhao GL, Wang LH, Zhou M: A study of induced abortion history and KAP of contraception in married women of reproductive age in city. Maternal and Child Health Care of China 2004, 19:97-99.

12. National population and family planning commission of China: Statistical report of family planning. [http://www.npfpc.gov.cn/cn/ detail.aspx?articleid $=090531 \mid 10017466820]$. accessed July 27, 2009

13. Family planning in China [http://www.medizin-ethik.ch/publik/ family planning.htm]. accessed March 27, 2009

14. Guo SF, Zhao FM, Zhang T, Li BH, Cui Y, Wu KS: Condom use among individuals of reproductive age and its influence factors. Chin J Public Health 2006, 22:7-8.

15. Xiao WF: A survey and analyses of reproductive health status of married rural women in China. Journal of ChangChun Medical 2005, 3:27-28.

\section{Pre-publication history}

The pre-publication history for this paper can be accessed here:

http://www.biomedcentral.com/1472-6874/9/23/prepub
Publish with Bio Med Central and every scientist can read your work free of charge

"BioMed Central will be the most significant development for disseminating the results of biomedical research in our lifetime. "

Sir Paul Nurse, Cancer Research UK

Your research papers will be:

- available free of charge to the entire biomedical community

- peer reviewed and published immediately upon acceptance

- cited in PubMed and archived on PubMed Central

- yours - you keep the copyright
BioMedcentral 